\title{
Investigation of Some Properties for Laminated Composite Used for Prosthetic Socket
}

\author{
Shereen A. Abdulrahman*, Qahtan A. Hamad, Jawad K. Oleiwi \\ Materials Engineering Dept., University of Technology-Iraq, Alsina'a street,10066 Baghdad, Iraq. \\ *Corresponding author Email: mae.19.27@ grad.uotechnology.edu.iq
}

\section{H I G H L I G H T S}

- Laminated composite specimens of the prosthetic sockets were made by vacuum molding technique.

- Types and No. of layers are most significant on the properties.

- Using natural fibers represent an alternative material to synthetic fibers in the composite prosthetic socket.

- The compression strength increased and the density decreased by using natural fibers.

\section{A R T I C L E IN F O}

Handling editor: Akram R. Jabur

Keywords:

Prosthetic Socket

Composite

Compression

Water Absorption

\section{A B S T R A C T}

\begin{abstract}
Polyester has been used as a prosthetic socket base. It is well documented that the raw material of the socket base should have exhibited good mechanical properties. Prosthetic socket is a device that connects an artificial limb with the amputee part. In this work, seven laminated composites were prepared using vacuum technique from polyester resin and reinforced with Jute, Carbon, Glass, and Perlon fibers. The objective of this study is to manufacture prosthetic sockets from different laminated composite materials (fibers reinforced polymer) to make high-strength and durable prosthetic socket design. The results showed that the best laminated composite specimens have three jute fiber layers with four carbon layers whose compression strength and hardness reach (67) MPa and (86) Shore$\mathrm{D}$, respectively. Also, the water absorption of the composite specimen of jute with carbon fibers is higher than that of the composite specimen of jute with glass fiber.
\end{abstract}

\section{Introduction}

Artificial limbs, also known as prostheses, are frequently used to help people who have had limbs amputated regain their appearance and functional activity. A socket, which surrounds the stump and to which the remaining components of the prosthesis are attached, is typically used to connect the residual limb and the prosthesis [1]. The prosthetic socket is the device that connects an artificial limb with the amputee part [2].

In prosthesis, fiber-reinforced polymer composites are the most widely used multi-phase materials. Furthermore, most of today's upper and lower limb prostheses are now made of composites with the underlying polymer matrix. These types of materials are beneficial because of their excellent strength to weight characteristics [3]. Natural fibers are preferred for their low density, high stiffness-to-weight ratio, low cost, high strength-to-weight ratio, and eco-friendly characteristics [4]. Jute is regarded as one of the most successful reinforcement for polymer composites due to several advantages, including ease of availability, low production costs, and adequate mechanical properties when compared to other fibers [5].

Human-made fibers that are produced by chemical synthesis are called synthetic fibers [6]. Fiberglass is the most common and most economical composite. The key characteristics of fiberglass are its durability and flexibility. Probably carbon is the most valuable composite for orthopedic equipment. It is very rigid and able to maintain its shape under stress due to its excellent strength under both tension and compression. The structural compromise of the carbon fibers is that the stiffness causes brittleness and low resistance to impact [7]. Trans tibial and its components are illustrated in Figure 1 [8].

Several research works were conducted in this field. Oleiwi et al. [9] used polymer composite materials PMMA:SR/PUR reinforced by carbon fibers $(\mathrm{CF})$ that were prepared as a suitable material for prosthetic foot, then mechanical properties were studied. The result showed that tensile strength and modulus of elasticity increased with increasing the ratio of carbon fibers because the fibers will carry and distribute most of the load applied on the specimens of composite material . Oleiwi et al. [10] studied the effect of increasing the number of jute reinforcing fibers layers on the mechanical properties, in addition to the constant number of perlon fibers layers. The result showed that the mechanical properties increase as the number of jute 
reinforcing layers increases . (Jumaa) made different types of laminated for below-knee prosthetic socket arranged as (4perlon +2 carbon fiber +4 perlon), $(3$ perlon +2 carbon fiber +3 perlon $)$, and ( 3 perlon +1 carbon fiber +3 perlon) to choose the perfect laminated socket. The results showed that the best one of the suggested lamination consists of (3perlon +1 carbon fiber +3 perlon) due to its safety and also it reduces the weight and the cost of the prosthetic socket [11]. The aim of this study is to improve the performance of prosthetic sockets by studying the effect of the number of jute reinforcing fibers (one, two, and three) layers, and the effect of adding glass or carbon to the best lamination (three jute fiber layers) on mechanical and physical properties.

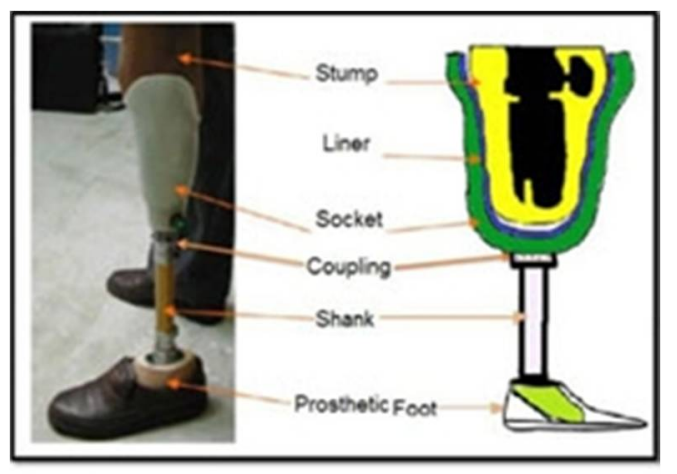

Figure 1: Trans-Tibial (below knee) prosthesis with components part [8]

\section{Materials and Equipment}

\subsection{Materials Used}

Materials used in the lamination of the below-knee socket for this study are polyester (manufactured by B-CHEM company), woven of jute fiber, carbon fabric that is unidirectional (a type of carbon reinforcement that is non-woven features all fibers running in a single, parallel direction which was manufactured by Ottobock company), glass fiber (used in this study manufactured by ottobock company and it is characterized by highly elastic, double-stretch fabric) and Perlon stockinet ( article name from the company is (623T5) manufactured by ottobock company). Other materials needed for the manufacturing of prosthetic sockets are polyvinyl alcohol PVA bags and materials for gypsum mold. The equipments used in this research are: jepson mold, vacuum forming, mechanical workshop, universal instrument machine, and sensitive weighting device.

\section{Procedure of Sample's Manufacturing}

1) Make gypsum mold sculpted, refined, and placed on the stand, and the connection is completed with the vacuum system through the pressure tubes.

2) Put the first piece of the PVA bag on the gypsum molds as the inner layer and close from the top and bottom. Suction of the air is done by the vacuum system between PVA and gypsum to prevent the formation of bubbles and to prevent adhesion between the resin and gypsum mold as shown in Figure 2-a.

3) The jute fiber, carbon fibers, and perlon stockinet were added according to the lamination lay-up as depicted in Table I as well as shown in Figure 2-b and c.

4) The outer PVA was put and the cotton thread was used to attach the PVC bag to keep the smaller tip on the valve. The vacuum system sucked the air between two bags and the top end was left open for the supply of resin.

5) The polyester resin was then mixed with the hardener according to the standard ratio (2\% of the resin) until obtaining a homogenous mixture, then the resulting matrix mixture was put inside the outside (PVA) bag, and the matrix was distributed homogenously over the area of lamination stockinet as shown in Figure 2-d.

6) Keep the vacuum device running until the composite material cold becomes hard and then the resulting lamination is removed from the gypsum mold.

Seven types of laminated composite material will be manufactured in vacuum machine which is shown in Table 1:

Table 1: Kinds of Composite Material

\begin{tabular}{llcl}
\hline $\begin{array}{c}\text { Lamination } \\
\text { name }\end{array}$ & \multicolumn{1}{c}{ Type of layers } & $\begin{array}{c}\text { Stacking } \\
\text { sequence }\end{array}$ & $\begin{array}{c}\text { Total number } \\
\text { of layers }\end{array}$ \\
\hline Laminate 1 & 2 perlon fiber -1 jute fiber - 2 perlon fiber & 1J & 5 layers \\
Laminate 2 & 2 perlon fiber - 2 jute fiber - 2 perlon fiber & 2J & 6 layers \\
\hline Laminate 3 & 2 perlon fiber - 3 jute fiber - 2 perlon fiber & 3J & 7 layers \\
\hline Laminate 4 & 2 perlon fiber - 2 carbon fiber - 3 jute fiber - 2 perlon fiber & 3J-2C & 9 layers \\
\hline Laminate 5 & 2 perlon fiber - 4 carbon fiber - 3 jute fiber - 2 perlon fiber & 3J-4C & 11 layers \\
\hline Laminate 6 & 2 perlon fiber - 2 fiber glass - 3 jute fiber - 2 perlon fiber & 3J-2G & 9 layers \\
Laminate 7 & 2 perlon fiber - 4 fiber glass - 3 jute fiber - 2 perlon fiber & 3J-4G & 11 layers \\
\hline
\end{tabular}




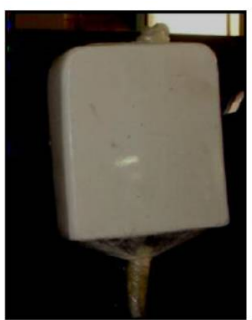

(a)

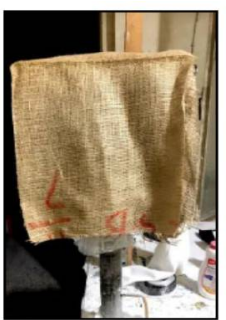

(b)

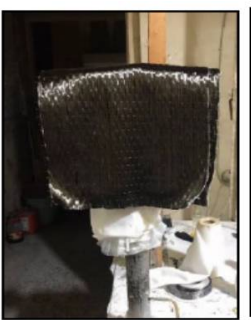

(c)

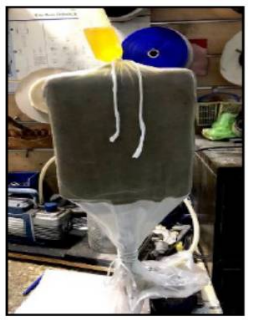

(d)

Figure 2: Procedure of making the samples

\section{Mechanical Test}

\subsection{Compression Test}

Compressive strength is the stress required to rupture a specimen under compression load. Failure of compression of the composite material depends on the properties of the matrix and reinforced materials such as volume fraction, shape, and interface as well as the size of reinforcing materials [12]. The Compression test was measured according to ASTM (D695) using a universal testing machine (model WDW 200 E), made in China and the load was applied until the break of the specimen occurred. This test was carried out in air at room temperature $(23 \pm 2)^{\circ} \mathrm{C}$, where five specimens were used for most tests and the final results represent the average of five specimens that were tested [13]. Figure 3 shows the specimens before and after the test and the instrument of the compression test that was used in this study.

\subsection{Hardness Test (Shore D)}

The hardness of the samples, which had to have a flat, plain surface, was calculated using Shore D. Samples have been cut into a diameter of $(50.8 \mathrm{~mm})$ and a thickness of $(4 \mathrm{~mm})$ in accordance with (ASTM D -2240) standard by Dorumeter hardness test [14], type (Shore D) with a load of $50 \mathrm{~N}$ was added and the depressing time of measuring was about (15) Sec. Each sample was tested five or seven times at different positions at the same time and the average value was taken. Figure 4 shows a sample of the specimens for the hardness test, standard specimen of hardness test, and the hardness device.

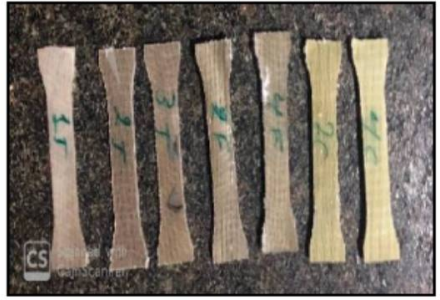

(a)

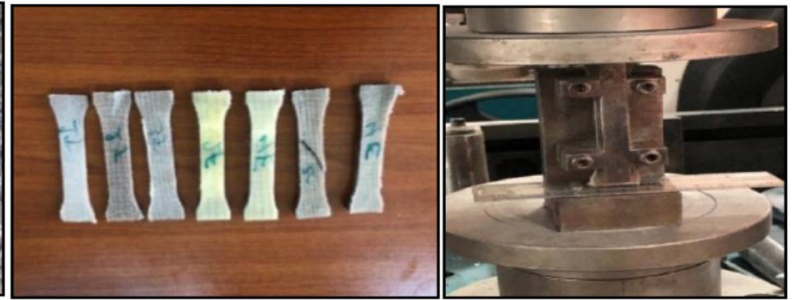

(c)

Figure 3: (a) Sample before test, (b) Sample after test, and (c) The compression test device

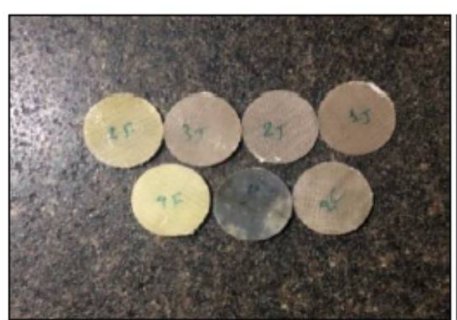

(a)

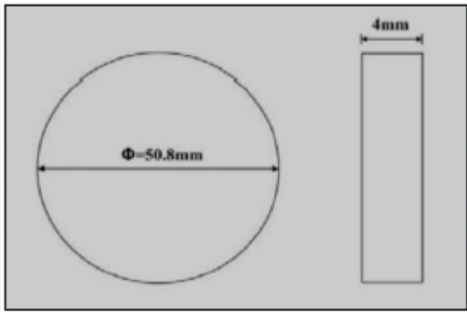

(b)

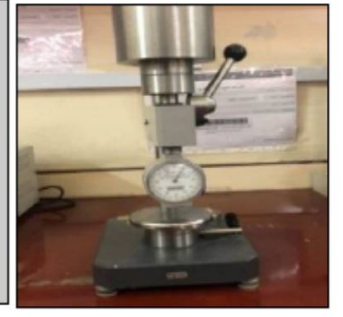

(c)

Figure 4: (a) Sample of the specimens for hardness test (b) Standard Specimen of Hardness Test, and(C) The hardness device

\section{Physical Properties}

\subsection{Density Test}

The density of composite samples indicates the lighter composite socket in this study. The samples have been prepared following ASTM standard (D-792) [15]. The samples weights were determined using Archimedes' theory by accurate balances of three digits' type: PS360/C/1 device of three digits' balances, as indicated in Figure 5. The specific gravity and density can be determined from Eq.s $(1 \& 2)$, respectively [16]. 
Density $=($ Specific gravity $) *(0.997 .5)$

Where : $\mathrm{m}_{1}$ : Mass of the sample in the air $(\mathrm{gm}) \mathrm{m}_{2}$ : Mass of the sample in water $(\mathrm{gm})$. W: Mass of partially immersing wire.

\subsection{Water Absorption Test}

The water absorption test was carried out following (ASTM D570) and the sample was immersed in distilled water under specific conditions of immersion times and temperature. The sample was completely immersed at room temperature of $(23 \pm 2)^{\circ} \mathrm{C}$ in a container of distilled water and left at the edge for $(24 \mathrm{hr})$. After that, the samples were taken out of the distilled water. Then all of the water had been wiped off from the surfaces with a dry cloth and then the sample was weighed by a digital balance, and water absorption was measured by applying Eq. (3) [17]. Figure 6 shows the standard sample of this test and experiential water absorption test samples [18].

$$
\text { Water Absorption Percentage: } \frac{(\mathrm{Ws}-\mathrm{Wd})}{\mathrm{Wd}} \times 100
$$

Where $\mathrm{W}_{\mathrm{d}}$ : Mass of specimen in the air. $\mathrm{W}_{\mathrm{s}}$ : Mass of the specimen after immersion in distilled water for ( $24 \mathrm{hr}$.).

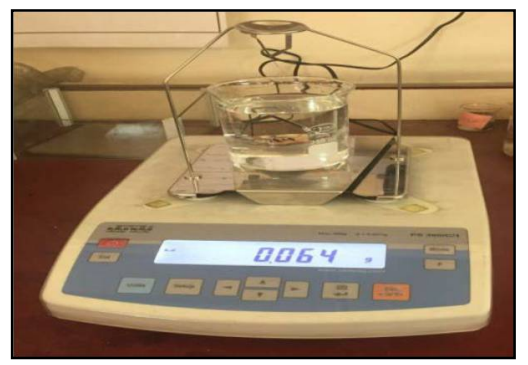

Figure 5: The density device

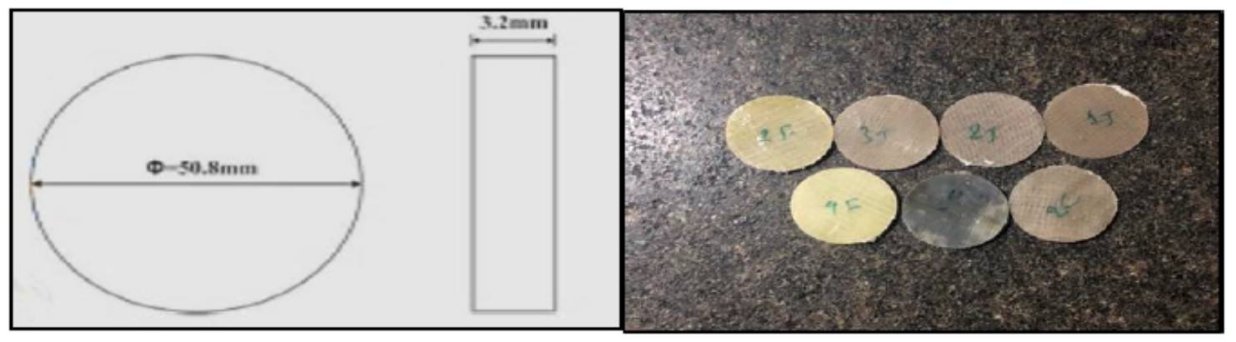

(a)

(b)

Figure 6: (a): The standard sample for water absorption test, (b): The experimental water absorption test samples

\section{Results and Discussion}

\subsection{Compression Test Results}

The effectiveness of adding layers of fiber to the compression strength of polyester resin is clarified in Figure 7. Firstly, from these figures, the compression strength of polyester resin increased as the number of jute fiber increases (the volume fraction increased) and reaching to (41MPa) for three layers of jute. The reason behind this behavior may be attributed to the nature of this fiber which has good compression strength. Moreover, from the same figure, it can be noticed that adding the glass fiber to the best lamination (three layers of jute fibers) leads to increase the compression strength more than the jute fiber alone. Also, this is due to the strengthening mechanism and the nature of bonding. In addition, this can be related to the compressive strength of glass fibers and the compressive strength of jute fibers which are much higher than polyester resin. The compression strength increases as the fibers absorb, transfer, and distribute the load uniformly throughout the crosssection. It is clear from the figure that the compression strength of specimens increases with increasing layers of carbon when they are added to jute fibers reaching to $(67 \mathrm{MPa})$ for three-four layers of jute and carbon, respectively. The fibers' strengthening mechanism and the bonding of fibers with polyester give the specimens higher compressive strength with more reinforcing layers [19]. This could be attributed to the fact that carbon fibers are characterized by their higher compressive strength than that of jute with glass and jute alone. Therefore, the compressive strength of laminated composite specimens is improved. The compression strength of hybrid laminate composite reinforced with the layers (jute - carbon) fibers is higher than that of the hybrid laminate composite with (Jute-Glass) fibers.

\subsection{Hardness Test Results}

The hardness is the ability of a material to resist penetration. Figure 8 illustrates the relationship between the hardness value obtained with the type and the number of reinforcement. The hardness value increases as the number of jute layers increased, and the value was about (76) Shore-D for three layers of jute fiber. This increase was due to the distribution of the 
test load on the fibers which reduced the penetration of the load to the surface of the composite material. Fibers lead to an increase in the modules of composite offering an increase in the hardness of the composite, since hardness is a function of the relative volume of fiber and modules [20, 21, 22]. From the same figure, adding the glass fiber to the jute fiber (the best lamination) leads to increase hardness more. This means that the Shore - D hardness value will increase as the number of layers of reinforcement materials (Jute with Glass) fibers increases. It was found that specimens with 3 layers of Jute with 4 layers of carbon fibers have the highest value of hardness (86 Shore-D). That is due to the fact that carbon fibers have higher mechanical properties, stiffer, and harder, as compared to the matrix polymer, glass with jute fibers, or jute fiber alone. Thus, the hardness values improved from (71- 86) Shore-D for one layer of jute fiber alone to three layers of jute with four layers of carbon, respectively. The addition of carbon to the best lamination leads to an increase in the hardness values more than glass when it was added to the best lamination.

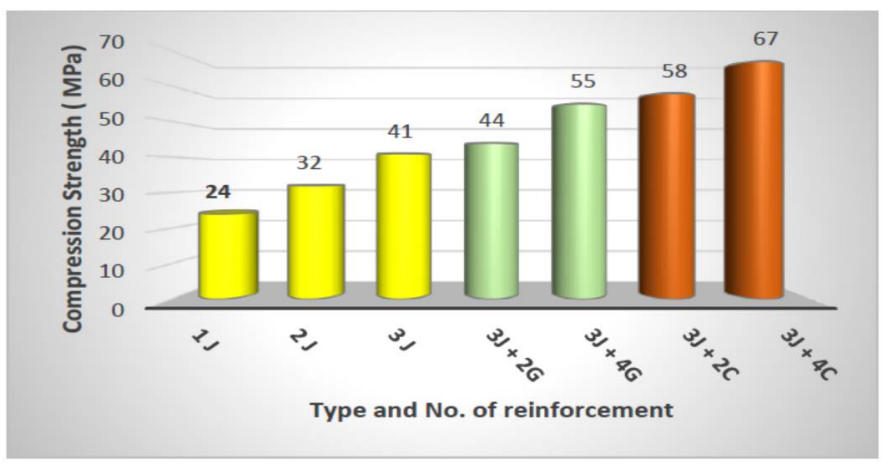

Figure 7: Compression Strength of Composites and Hybrid Laminate Composites having Different Layers of Reinforcements

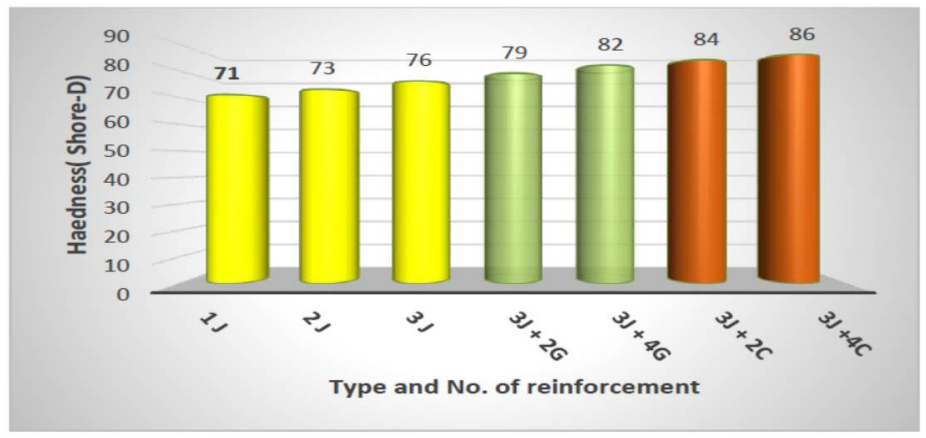

Figure 8: Hardness (Shore-D) of Composites and Hybrid Laminate Composites having Different Layers of Reinforcements

\section{Physical Tests Results}

Physical tests involve the density and water absorption tests carried out for polymer composites samples.

\subsection{Density Test Results}

The density of laminated composite specimen was measured by the Archimedes method. It can be noticed from Figure 9 that the values of density decrease with increasing the volume fraction for jute fiber (number of layers), because the density of jute fibers is lower than that of polyester. Density measurement for laminated composite is an important indicator to know the lighter composite materials [16]. Typically, composite materials are lighter than metals. This is one of the reasons behind the use of composite materials in engineering materials. Specimens of jute with glass lead to increase the density slightly and this is due to the presence of glass fibers. Density was about $\left(1.272 \mathrm{~g} / \mathrm{m}^{3}\right)$ for four layers of glass with 3 layers of jute fibers. Generally, jute fibers with added carbon have a density lower than that of specimens of jute with glass fibers because the density of carbon is lower than that of glass fiber and higher than that of the polyester matrix. The density of glass fibers is higher than the density of carbon fiber that has been mentioned previously [23,24]. So carbon leads to decreased density as compared with glass when added to the best lamination. In general, density is equal to $\left(1.138 \mathrm{~g} / \mathrm{cm}^{3}\right)$ for specimens with jute fibers alone.

\subsection{Water Absorption Results}

The results of the water absorption test of the polyester and all the fabricated composite are shown in Figure 10. It has been noticed that the water absorption will be decreased as the number of jute layers increases to reach $(0.75 \%)$ for three layers of jute fiber. The composite with jute fiber absorbed more water than the composites with hybrid (glass fiber and jute) [25]. Adding glass to three layers of jute fibers leads to slightly decreased water absorption reaching $0.688 \%$ for three layers of jute with four layers of glass fibers $(3 \mathrm{~J}+4 \mathrm{G})$. However, adding carbon fiber to the best lamination leads to a higher rate of 
water absorption than that of specimens of jute with glass fibers since a composite specimen of jute with carbon fibers has a density lower than that of specimens of jute with glass fibers. Density decreases with increased moisture absorption [26]. Three layers of jute with four layers of glass $(3 \mathrm{~J}+4 \mathrm{G})$ specimen have the lower value of water absorption, which equals $(0.688 \%)$, while composite specimen for three layers of jute with four layers of carbon $(3 \mathrm{~J}+4 \mathrm{C})$ has a higher value than $(3 \mathrm{~J}+4 \mathrm{G}) \mathrm{reaching}$ $(1.666 \%)$.

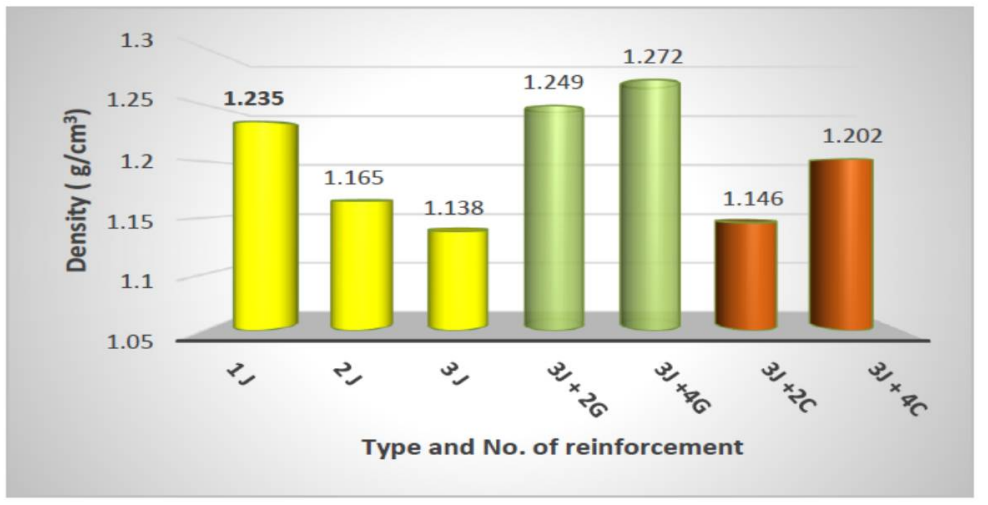

Figure 9: Density of Composites and Hybrid Laminate Composites having Different Layers of Reinforcements

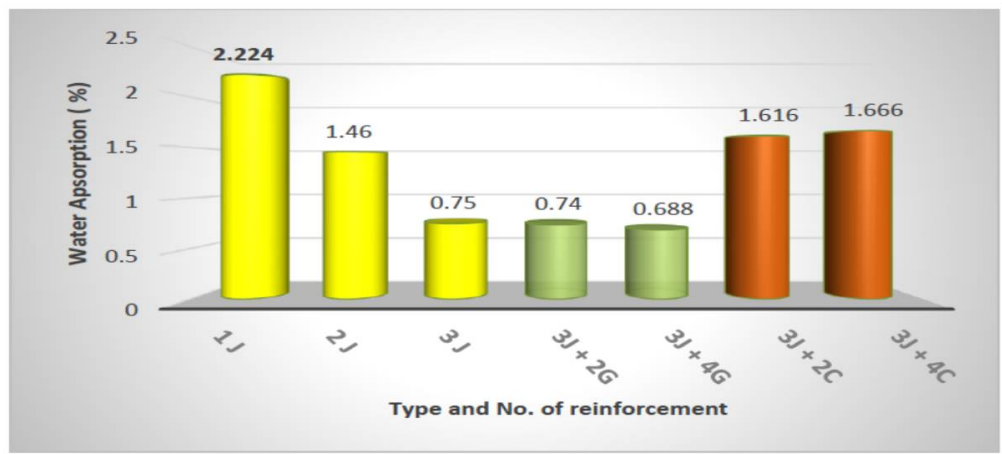

Figure 10: Water Absorption of Composites and Hybrid Laminate Composites having Different Layers of Reinforcements.

\section{Conclusions}

1. Compression strength increases with the increasing number of fiber layers, where the composite specimen of jute with carbon fibers is higher than a composite specimen of jute with glass fibers or jute fiber alone and the largest value is (67 $\mathrm{MPa}$.) for three layers of jute with four layers of carbon fiber (3J+4C).

2. Hardness increases with increasing volume fraction of fibers (number of fiber layers), where the composite specimen of jute with carbon fibers is higher than a composite specimen of jute with glass fibers or jute fiber alone and the highest value of the hardness was ( 86 Shore-D) for $(3 \mathrm{~J}+4 \mathrm{C})$ specimens.

3. The density of polyester reinforced with jute fibers decreased as its number increased. Carbon with jute fiber composite specimen decreased density slightly as compared to the case when adding glass to jute fiber. Therefore, lighter specimens that have 3 layers of jute fibers reach $(1.138 \mathrm{~g} / \mathrm{cm} 3)$

4. The rate of water absorption of a composite specimen of jute with carbon fibers is higher than that of a composite specimen of jute with glass fiber $(3 \mathrm{~J}+4 \mathrm{C})$. The lower values were found with specimens of three layers of jute alone which equals $(0.74 \%)$.

Author contribution All authors contributed equally to this work.

\section{Funding}

This research received no specific grant from any funding agency in the public, commercial, or not-for-profit sectors.

Data availability statement

The data that support the findings of this study are available on request from the corresponding author.

Conflicts of interest

The authors declare that there is no conflict of interest.

\section{References}

[1] M. B. Silver-thorn, J. W. Steege, D. S. Childress, A review of prosthetic interface stress investigations, J. Rehabil. Res. Dev., 33 (1996) 253-266. 
[2] D. P. Reynolds , M. Lord, Interface load analysis for computer- added design of below-knee prosthetic sockets, Med. Biol. Eng. Comput.,. 30 (1992) 419-426. http://dx.doi.org/10.1007/BF02446180

[3] M. S. Scholz, J.P. Blanchfield, L.D. Bloom, B.H. Coburn, M. Elkington, J.D. Fuller, M.E. Gilbert, S.A. Muflahi, M.F. Pernice, S.I. Rae, J.A. Trevarthen, S.C. White, P.M. Weaver, I.P. Bond, The use of composite materials in modern orthopedic medicine and prosthetic devices: A review, Compos. Sci. Technol., 71 (2011) $1791-1803$. https://doi.org/10.1016/j.compscitech.2011.08.017

[4] J. K. Pandey, S. H. Ahn, C. S. Lee, A. K. Mohanty, M. Misra, Recent advances in the application of natural fiber based composites, Macromol. Mater. Eng., 295 (2010) 975-989. https://doi.org/10.1002/mame.201000095

[5] R. K. Yadav, A study of mechanical behavior of surface modified jute fiber reinforced epoxy composites, Nat. Ins. Tec., BTech Thesis., Rourkela, (2013).

[6] T. P. Sathishkumar, J. Naveen, S. Satheeshkumar, Hybrid fiber reinforced polymer composites - A review, J. Reinf. Plast. Compos., 33 (2014) 454-471. https://doi.org/10.1177/0731684413516393

[7] D. A. Berry, Composite Materials for Orthotics and Prosthetics, J. Prosthetists Orthot., 40 (1987) 35-43.

[8] I. R. Abd Al-razaq, K. K. Resan, Y. K. Ibrahim, Modular socket system versus vacuum technique in transtibial prosthetic socket, Int. J. Energy Environ., 7 (2016) 457-468.

[9] J. K. Oleiwi , A. Namah. Hadi, Design of prosthetic foot from polymer materials reinforced by carbon Fibers, Eng. Technol. J., 34 (2016) 1744-1754. https://doi.org/10.30684/etj.34.9A.3

[10] J. Kadhim. Oleiwi , S. J. Ahmed, Studying the tensile and buckling for PMMA reinforced by jute fibers for prosthetic pylon, Eng. Technol. J, 34 (2016) 111-122. https://doi.org/10.30684/etj.34.1A.10

[11] J. S. Chiad, Study the impact behavior of the prosthetic lower limb lamination materials due to low velocity impactor, proceeding ASME 2014 12Th Bienn. Conf. Eng. Syst. Des. Anal., 23 (2014) 10. https://doi.org/10.1115/ESDA201420007

[12] S. Feih, A. P. Mouritz, Z. Mathys, A.G. Gibson, Tensile strength modeling of glass fiber - polymer composites in fire, J. of Composite Mater., 41 (2007). https://doi.org/10.1177/0021998307075461

[13] Annual Book of ASTM Standard Standard test method for compressive properties of rigid plastics, D695-02a, (2002).

[14] Annual Book of ASTM Standard, Standard test method for plastics properties-durometer hardness, D $2240-03$ (2003).

[15] E. Charles, Jr. Carraher, Seymour Carraher's, Polymer chemistry, Seventh Edition by Taylor \& Francis Group, LLC, Florida, U.S.A, Samriddhi .j. phys. sci. Eng. technol., (2008) 776. https://doi.org/10.1201/9781420051032

[16] ASTM, Standard Test Method for Density and Specific Gravity (Relative Density) of Plastics by Displacement D792-08, New York, (2004). http://dx.doi.org/10.1520/D0792-08.2

[17] S.S.F. Naoum, The Effect of Curing Time and Photo Activation Methods on the Wear Rate of Light Activated, M.Sc. thesis, University of Baghdad, College of Dentistry, Iraq, (2004).

[18] Standard Test Method for Water Absorption of Plastics, (2018) 570-98.

[19] P. K. Mallick, Fiber-Reinforced Composite, Mater. Des., Int. Standard Book, 3rd edition, Boca Raton, (2007) 638. https://doi.org/10.1201/9781420005981

[20] F. Ronkay, Impact of fiber reinforced on polymer blend properties, Soc. Pla. Eng., (2011).

[21] F. Ronkay, L. Mészáros, G. Jánoki, T. Czvikovszky, The effect of pre-electron beam irradiation of HDPE on the thermal and mechanical properties of HDPE/PET blends, Mater. Sci. Forum, 659 (2010) 85-90. http://dx.doi.org/10.4028/www.scientific.net/MSF.659.85

[22] S. D. Pandita, X. Yuan, M. A. Manan, C. H. Lau, A. S. Subramanian, J. Wei, Evaluation of jute/glass hybrid composite sandwich: Water resistance, impact properties and life cycle assessment, J. Reinf. Plast. Compos., 33 (2014) 14-25. https://dx.doi.org/10.1177/0731684413505349

[23] M. J. Jweeg , S. H. Ameen, Experimental and theoretical investigations of dorsiflexion angle and life of an ankle-foot orthosis made from (Perlon/Carbon Fiber/Acrylic) and polypropylene materials, J., 11 (2011) 305-310.

[24] M. J. Jweeg, A. A. Alhumandy, H.A. Hamzah, Material characterization and stress analysis of openings in Syme's prosthetics, Int. J. Mech. Mechatron. Eng., 17 (2018).

[25] R. A. Braga , P. A. A. Magalhaes, Analysis of the mechanical and thermal properties of jute and glass fiber as reinforcement epoxy hybrid composites, Mater. Sci. Eng. C, 56 (2015) $269-273$. https://doi.org/10.1016/j.msec.2015.06.031

[26] S. Supreeth, B. Vinod , L. J. Sudev., Effect of fiber length on thermal properties of PALF reinforced bisphenol: A composite, Int .J. Sci. Technol. Res., 2 (2014) 229. 